\title{
The possibility of a free-will defence for the problem of natural evil
}

\author{
T. J. MAWSON \\ St Peter's College, Oxford, OX1 2DL
}

\begin{abstract}
In this paper, I consider various arguments to the effect that natural evils are necessary for there to be created agents with free will of the sort that the traditional free-will defence for the problem of moral evil suggests we enjoy - arguments based on the idea that evil-doing requires the doer to use natural means in their agency. I conclude that, despite prima facie plausibility, these arguments do not, in fact, work. I provide my own argument for there being no possible world in which creatures enjoying this sort of freedom exist yet suffer no natural evil, and conclude that the way is thus open for extending the free-will defence to the problem of natural evil.
\end{abstract}

\section{Introduction}

In everyday life we make a conceptual distinction between two categories of evil - moral and natural - and we suppose that both sorts occur in our world. Murder and child abuse would be taken as paradigmatic instances of moral evil and earthquake and disease as paradigmatic instances of natural evil. We may best crystallize the understanding by which we categorize evils as moral or natural by saying that we take an instance of suffering to be a moral evil insofar as we suppose that it may be blamed on some non-divine agent or agents, and we take an instance of suffering to be a natural evil insofar as we suppose that it may not. In what follows, I shall be assuming that this everyday practice of ours is right: our universe does indeed contain moral and natural evil thus understood and therefore the problem of moral evil (why would an omnipotent and perfectly good God (henceforth simply 'God') create a world with moral evil in it?) is, at least initially, distinct from the problem of natural evil - why would God create a world with natural evil in it?

On classical theism (henceforth simply 'theism'), God's creative act is His setting up the initial or boundary conditions of the universe and His laying down and sustaining the laws of nature which, randomness and libertarian free choices 
(if there be such things) aside, dictate how it evolves from that initial state or within those boundary conditions. So, on theism, to categorize an instance of suffering as a moral evil is to posit some blameworthy agency standing between God's creative act and the evil in question; to categorize an instance of suffering as a natural evil is to deny any such agency as even a proximate cause for the suffering in question. Thus, to categorize an instance of suffering as a moral evil is to raise the possibility that the moral responsibility due for the evil in question may be entirely attributed to a non-divine agent, rather than needing to be traced back to God.

The traditional free-will defence for the problem of moral evil suggests that the freedom non-divine agents, such as ourselves, enjoy is a good; and it is a good that is good enough to be worth the moral evils to which it gives rise, or at least it is good enough to render us not unreasonable in believing that God would have been justified in creating a world such as ours. To categorize an instance of suffering as a natural evil is to deny that there is any blameworthy non-divine agent standing between God's creative act and the evil in question, and is thus to deny the possibility that any blame due for it may be apportioned to an agent other than God. For moral evils the buck may stop before God: if the free-will defence works, it does. For natural evils any buck must stop with God. And prima facie natural evils do indeed present a buck - they are, after all, evils - and thus it may seem that there is a fairly direct route from the existence of them to the nonexistence of God, a route which bypasses the territory of the free-will defence. An omnipotent being could have exercised His free will by creating a different universe, one in which the initial or boundary conditions and the laws of nature (or randomness) were different and thus did not lead to any natural evil; a perfectly benevolent being would have wanted to create such a universe; thus there cannot be an omnipotent and perfectly benevolent God.

The problem of moral evil is in part the problem of showing that moral evil, or at least the real possibility of moral evil, is logically necessary for the existence of a good or goods which is or are at least as good as the evils are bad, and thus can be said to outweigh them in the great scheme of things, or at least that the proportion of evil relative to good is not so great as to make most reasonable the view that God would not have been morally justified in risking creating this universe. On the free-will defence, this good (or at least one of these goods) is the freedom that certain non-divine agents such as ourselves enjoy. The problem of natural evil is in part the problem of showing that natural evils are logically necessary for the existence of a good or goods which is or are at least as good as the evils are bad and thus may be said to outweigh them in the great scheme of things, or at least is or are good enough to mean that it is not most reasonable to think that God would not have been morally justified in risking creating this universe. For those enamoured of the free-will defence for the problem of moral evil, it will be attractively 'tidy' then to argue that natural evils are logically necessary for there to 
be non-divine agents enjoying freedom of the sort the free-will defence posits. Can such an argument be made to work?

The answer to this question is not obvious. It may be obvious that one would not be free to murder someone if God prevented one from ever having the thought that one might, or even if, having allowed one the thought, He then frustrated every attempt one made to actualize the possibility-Humeanmiraculously intervening, turning one's knife into harmless jelly before its point reached its target, etc. And from this it is easy to see that in a world where, as one might say, God 'regularly Humean-miraculously' intervened to prevent anyone murdering anyone (or in one where, of natural necessity, nobody ever murdered anyone), the creatures inhabiting that world would thus have been completely denied the freedom to murder one another. And it is easy to see the same point being made mutatis mutandis for all evil actions. Nevertheless, it is not obvious that the possibility is open to extend the free-will defence to natural evils as it is not obvious that there is no possible world in which people still have the freedom necessary to perform morally evil acts such as murder, yet in which there are no natural evils such as blameless accidental deaths. It is certainly hard to imagine a world in which there are moral evils (or at least the real possibility of them) but no natural evils. Yet it is not obviously so hard as to be impossible, and it is the impossibility of imagining (without contradiction) a world with moral evils (or at least their real possibility) yet no natural evils that the argument for extending the free-will defence to natural evils requires. To open the possibility of extending the free-will defence to natural evils, we therefore need to try to imagine a world in which at least some moral evils are really possible (and thus one in which there is at least some free will of the sort the free-will defence posits we enjoy) and yet in which there are no natural evils, fail in this task, and show how our failure is due to a contradiction inherent in it. This is what we shall spend the rest of the paper trying to do.

\section{The search for a free-will defence for the problem of natural evil}

Let us begin then by assuming for a contradiction that there is a possible world in which a certain Mr A and a certain Ms B live, and it is a world like ours save that nobody is ever harmed by accident; they are only harmed as the result of malice. In this world, A forms the evil desire to murder B; he chooses to give in to this desire rather than do what he knows he ought to do, restrain himself; and thus he decides to try to kill her. Would it really be possible for A to action his desire to murder B? We might argue as follows.

In this world, A could not push a boulder off a mountainside as B walked below, expecting her to be in any way damaged by it as it fell. A's is a world without natural evil, so it must be a world in which when falling boulders hit people they turn to dust or some such harmless material, damaging no-one. In A's universe, 
this must be true of even the largest and most robust boulders, ones which, when they hit things physically similar to B but of moral insignificance, smash them completely. He could not (even had guns been invented in his universe) raise a gun to B's head and pull the trigger expecting the bullet that emerged from the barrel to hurt her. He would know that projectiles of all sorts behave as boulders do when they come into contact with living people. The general point is that $\mathrm{A}$ cannot harm B without relying on the natural properties of some physical intermediary - a boulder, a gun, and (most fundamentally) B's body - but in A's universe as there are ex hypothesi no natural evils, there are no physical intermediaries with suitable properties. In a universe with no natural evils, neither A nor anyone else would ever be able to implement a desire to harm anyone. Such a world would be one without any possibility of moral evil, and thus one without any freedom of the sort the free-will defence for moral evils posits we enjoy. We have found our contradiction.

Sadly, this argument is too quick. We may modify our description of A and B's world in the following way to avoid it. We may suppose that A and B inhabit a world where at least some objects have two sets of properties, the one which is true of them when they have no blameworthy agency as a cause of their current state, and the one which is true of them when they have blameworthy agency as a cause of their current state. In A and B's world, it is not true that whenever a boulder falls on someone it fails to harm them. What is true is that, whenever a boulder falls on someone as a result of causes that have no blameworthy agency as a part it dissipates harmlessly on impact; whenever a similar boulder falls on someone as a result of some blameworthy action it damages them. The same goes mutatis mutandis for bullets and so on.

We must ask a question about A and B's world as we are now imagining it: what is it about boulders and bullets that makes them especially suitable implements for carrying through blameworthy intentions? There are two possibilities: nothing or something. We might seem to be able to posit a completely magical world in which any object may be used for harm: in such a world, waving a flower at someone whilst willing their head blown apart would produce the same effect as firing both barrels of a shotgun into their face from five yards with the same intention. But it could be argued that such a world would be one in which actions would not be possible. For the real possibility of blameworthy agency (without which there could not be moral evils and hence - ex hypothesi-there would not be freedom of the sort the free-will defence suggests we enjoy), we have to preserve the distinction between wishing that harm would befall someone, deciding to act on that wish, and doing so. It could be argued that in a completely magical world these distinctions would break down. As soon as one wished someone harmed, it would happen. Let us assume for the moment that this argument is sound (we will return to it later) and so let us describe A and B's world as one where there is something about boulders and bullets that makes them especially 
suitable implements for carrying through one's blameworthy intentions, i.e. let us imagine that A and B's world is what we might call 'partially magical'. In it, some objects have the property of being invariably harmless (small amounts of water, whether they are taken voluntarily or whether they are forced on one by someone who wishes them to be fatal, do not harm one); other objects (e.g. falling boulders and bullets) are variably harmful depending on the intentions of those who use them.

In their world as we are now imagining it, A could choose to implement his evil desire to kill B by pushing a boulder off a mountainside in her direction or by firing a gun at her head. (He could not choose to implement his evil desire to kill $\mathrm{B}$ by waving a flower at her with the same evil intention.) Here then, we might think, we have managed to describe a world with no natural evils, only moral ones - a world in which the residents have the sort of freedom posited as worth the evils which are (or which the real possibility of is) a necessary condition of it by the free-will defence, yet in which they also have the benefit of never suffering any natural evil.

Richard Swinburne offers us an argument against the coherence of this. ${ }^{1}$ Swinburne argues that without actual (and fairly widespread) experiences of harm befalling people, we would not know what actions would harm others and hence could not choose to harm others. Against the suggestion that moral evils alone might be sufficient to provide us with the experiences that are necessary for the relevant knowledge, Swinburne says this:

\footnotetext{
[F]or any evil which men knowingly inflict on each other, there must have been a first time in human history at which this was done. There must have been a first murder, a first murder by cyanide poisoning, a first deliberate humiliation, and so on. The malevolent agent in each case knows the consequence of the result of his action (e.g. that imbibing cyanide will lead to death). Ex hypothesi, he cannot know this through having seen an agent give another cyanide for this purpose. His knowledge that cyanide poisoning caused death must come from his having seen or others having told him that taking cyanide accidentally led to death. ... What applies to the malevolent agent also applies to the man who knowingly refrains from inflicting evil on another or stops evil occurring to another. There must be naturally occurring evils (i.e. evils not deliberately caused by men) if men are to know how to cause evils themselves or are to prevent evil occurring. ${ }^{2}$
}

We might respond to the argument given in this quotation first by considering that it seems easy to imagine A in our partially magical world being the first person to use cyanide to poison someone deliberately without his having any awareness of unintentional poisonings occurring in the past. We may, it seems, imagine that, whilst not having the concept of poisoning as such, A nevertheless wonders whether getting someone to ingest certain substances might be a way to kill her. Thus, intending to kill $\mathrm{B}$, each morning he picks one of the substances he finds around his kitchen and deliberately dissolves a small amount of it into a 
drink which he is in the habit of preparing for her, as he does so willing that it be a substance that will prove fatal. One day he gets lucky, as he thinks of it, by picking up a bottle of cyanide (which previously he and everyone else has used merely as a substitute for grated almonds). Thus, he discovers that cyanide has the property of being harmless when used as an ingredient in cakes prepared with no malevolent intention and harmful when used as an ingredient in drinks prepared with the intention that they harm. Thus he learns that cyanide may be categorized - along with falling boulders, and bullets - as variably harmful.

However, Swinburne would surely argue, this just makes the problem more general. How was it that A was able to form the intention to kill $\mathrm{B}$ ? Only by having seen or heard of other killings surely. Whilst we may, of course, posit that the killings A has seen or heard of are also moral evils, someone must have been the first to form the intention to kill another person (unless the universe is of infinite age and a certain character perhaps) and that person - ex hypothesi-could not have got the concept of killing from observing any deaths brought about by another blameworthy agent, so he would need to have got it from observing a natural evil, an accidental killing. The same point may be made for the acquisition of the concepts of harming or frustrating someone, concepts which the residents of the partially magical world we are now imagining A and B inhabiting must have before they can (by trial and error) acquire knowledge that certain events may be made to harm and frustrate people when they are initiated with the intention of doing so. What are we to make of this argument?

We may observe that accepting this argument concerning the alleged impossibility of a first malefactor in a world without natural evil requires us to assume that it is beyond the power of God to make the concepts required for malevolence innate for any resident of a partially magical world. ${ }^{3}$ Yet whatever plausible account one gives of the conditions one must satisfy in order to possess a concept, it is not logically impossible that God arrange a world where someone finds themselves satisfying those conditions for the concepts required for malevolence without any prior experience of their instantiation. ${ }^{4}$ One might insist that one cannot - of logical necessity (causal necessity of course will not do) possess the concept of a person's being harmed, frustrated, or killed without direct or indirect (i.e. through testimony) experience of harm, frustration, or death befalling someone, but this is implausible. Even if it is true that 'there's nothing in the mind that was not first in the senses', it is only contingently true; Locke was surely right to take the question of whether or not we have innate ideas as an empirical question, i.e. to assume that in some possible worlds we do. The question of whether or not we have innate knowledge by contrast is perhaps one which can be answered negatively a priori. ${ }^{5}$ To consider arguments to the effect that we cannot, would take us well beyond the scope of this paper.

Fortunately, we do not need to consider them in order to proceed, for we may observe that one does not need knowledge of harm having befallen someone in 
the past to form the intention to harm someone in the future any more than one needs to know that something has flown in the past in order to form the intention to fly in the future. It may be suggested that if one had acquired one's concept of flight in a manner other than by experience one would not know what to do in order to implement an intention to fly, the same going for the concept of harm and so on. But, as our example of A's discovering cyanide's power to kill shows, one does not need this to move from malevolence to malfeasance-one may simply use trial and error. Of course, as we depicted it, A started this process of trial and error by wondering whether getting someone to ingest certain substances might be a way to kill them and we may legitimately ask why he entertained that possibility rather than any of the infinite number of other logically possible effects that ingesting substances might produce. Given that one cannot intend to harm another by performing a certain action unless one thinks that that action makes it at least slightly more likely that the other will be harmed than benefited, it is logically necessary that one have some beliefs about how one is more likely to be able to harm than benefit people by one's actions if one is to intend to harm people and thus to perform a process of trial-and-error discovery of the sort described. It could be argued then that in order for A to get started on such a process of trial and error, he must 'frame' some hypotheses as more probable than others, i.e. he must have some prior beliefs about the physical probabilities of the various logically possible outcomes. For the first malefactor, these beliefs could not have come from observing intended harm befalling someone; they would have to have been a priori judgements of physical probability.

If this argument is sound, it seems that, when pushed, we might need to say that God must have created A and B's world as one in which at least one resident had certain beliefs about what consequences performing certain acts with the intention that they harm others would be more or less likely to bring. But even if we are pushed to admit this, it does not seem overly troublesome. It is not impossible after all that God could have created A and B's world as one in which each resident had an innate belief that cyanide would kill the person who consumed it if and only if it were administered with the intention that it do so. As God would have given her this belief because it was true, so on certain externalist accounts of knowledge such a belief would in fact count as knowledge (even though it would not do so on the internalist account that Swinburne favours) ${ }^{6}$ Yet it seems that, knowledge or not, this belief would be sufficient for the residents of A and B's world to move from malevolence to malfeasance; even a luckily true belief for which one has no justification whatsoever does for that. With the caveat that Swinburne's argument as we have hitherto presented it might not have been designed to do so, we may say then that a Swinburne-style argument from the alleged impossibility of a first malefactor in a world without natural evil does not on its own show that there could not be a world with moral evils but no natural 
evils such as the one which we seem to have succeeded in imagining A and B inhabiting. We need another argument.

Realism about natural science suggests that the universe operates according to natural laws, laws which are independent of our beliefs about them and which the history of natural science shows it to be describing with increasing accuracy. There is no obvious necessity that the natural laws by which the universe operates be comprehensible to us imposed by the fact that we survive without constant Humean-miraculous intervention on our behalf or something effectively equivalent. However, there is an obvious necessity that the natural laws by which the universe operates be such as to allow comprehensible approximations which are sufficient for the purposes of everyday life imposed by the fact that we survive without constant Humean-miraculous intervention on our behalf or something effectively equivalent. The natural laws must be such as to allow us to construct what we might call a folk science with its quasi-laws, that is to say laws which generally hold true within the realm that we inhabit and care about, the realm of what we might call slow-moving medium-sized dry goods. Quasi-laws sufficient for us to build a folk science must be comprehensible to us if we are to perform actions. All actions are directed towards bringing about a change in one's environment. To be able to intend to bring about a change in one's environment requires one to have some reasonable beliefs concerning what would happen to one's environment anyway, and how this would be affected were one to do one thing rather than another. Thus, it is a necessary condition of performing actions that one understand one's environment in at least a folk-scientific way. Without understandable natural quasi-laws, the residents of a world would not have any freedom of the sort the free-will defence posits we enjoy. If all of this were right, could it be used to call into question the coherence of our description of the world that we are now imagining A and B inhabiting as one without natural evil? It could.

In A and B's world as we are now imagining it, there operates what might be called a 'spiritual quasi-law' that nobody is ever harmed by objects the state of which is not in part a result of non-divine blameworthy agency. This spiritual quasi-law cannot be integrated with any folk-scientific world view that the residents of A and B's world could develop (hence the epithet 'spiritual') for there is no non-gerrymandered natural property that earthquakes in areas inhabited by people for whose presence somebody is to be blamed, maliciously pushed boulders, cyanide used with the intention that it harm, bullets fired at people with the intention that they kill, and a potentially infinite number of other things have in common. One might thus argue that if A and B are to live in a world comprehensible enough for them to navigate their way through it by performing actions, then there cannot in fact be a spiritual quasi-law of the level of generality that nobody is ever harmed by objects, the state of which is not in part a result of non-divine blameworthy agency. This would destroy 
the uniformity of nature which is needed as a background for actions to be possible.

One might argue this, but it would not be persuasive. For it could be argued that although the residents of A and B's world could not indeed completely understand what was happening to them in naturalistic terms, it would not follow from this that they could not form a world view sufficient to enable them to perform actions; after all, there would still be some understandable regularity. The natural quasi-laws with which the residents made sense of their everyday experiences such as 'falling boulders smash things' would occasionally be 'trumped' by the spiritual quasi-law that nobody is harmed except as a result of blameworthy intention. However, as long as God contrived to make the occasions when people were hit by accidentally falling boulders and the like sufficiently few and far between (which He could do without entirely eliminating freedom of the sort the free-will defence for moral evil suggests we enjoy), there would still be enough consistency of experience to enable the residents to form a folk science and thus understand in a folk-scientific way their experience, navigating a course through their world. The difference between A and B's world and ours would simply be that God was in effect performing Humean miracles with a far greater frequency in A and B's world than He does in ours - 'in effect' as (at least on certain theories) God may have made A and B's world such that the spiritual quasi-law's trumping the natural quasi-laws is in fact a natural necessity imposed by natural laws of their world so complicated that they could never understand them. In any case, this 'regular Humean-miraculous' intervention, or something effectively equivalent, seems to leave adequate space for A and B to develop folk-scientific 'rules of thumb' and thus for them to be agents. If so, then if the operation of this spiritual quasi-law threatens A and B's freedom, it does so less directly. Let us look at an argument for how this might happen; it is the argument that Swinburne uses to augment the one we have previously discussed.

There is some plausibility in the suggestion that to the extent that God allows His existence and character to become manifest to a finite agent He detracts from that agent's freedom unless He increases that agent's natural tendency to evil - let us follow Swinburne in referring to this as 'depravity' ${ }^{7}$ This is because there is some plausibility in suggestions such as the following.

If we suppose one's depravity to be constant between the cases, one would not be as free to run a red light if one knew that a policeman was sitting in the front passenger seat of one's car as if one thought oneself alone and unobserved ${ }^{8}$ and if one knew that one's other passengers were the Bishop of Oxford and Richard Swinburne, one's freedom to run the red light would be reduced still further. If this sort of thought is correct, then it seems we may extrapolate from it and say that if one knew that one had an omnipotent, omniscient, and perfectly just God figuratively speaking 'in' the car too, one's freedom to run the red light would be 
eliminated entirely. We need 'epistemic distance' in order to have a free choice between good and evil. ${ }^{9}$ Or rather, we need a suitable balance to be struck between our epistemic distance and our depravity. Thus, 'the more uncertainty there is about the existence of God, the more it is possible for us to be naturally good people who still have a free choice between right and wrong'. ${ }^{10}$

The world that we are now positing A and B as inhabiting is a world where, were the residents even passably aware of their surroundings (as they must be by our previous argument if they are to develop a folk science and hence if they are to be able to perform actions), they could not but be aware of the spiritual quasi-law that dictated that they never suffered save as the result of one of their number deciding to action an evil intention. There being nothing that could feature in the folk-scientific world view that the residents were able to form that would subsume all those instances in which objects displayed one of their sets of properties and those instances in which they displayed the other, would draw to their attention a 'suspicious' serendipity in nature and a 'suspicious' contrivance to allow them to exercise their free choices. These facts would lead them ineluctably to posit a supernatural entity either 'regularly Humean-miraculously' intervening or having arranged the laws of nature so that they were maximally fine-tuned to their purposes. Their world would be one manifestly under the control of a powerful and just sovereign, a world in which God's hiddenness was so much less than it is in our world that this would entirely remove freedom of the sort the freewill defence suggests we enjoy unless the residents were considerably more depraved than we are, something which would be in itself a natural evil. Swinburne thus closes his argument with the assertion that it is 'in no way obvious that it would be better for God to replace disease by such an increase of inbuilt depravity ... . Rather, I would have thought the reverse' ${ }^{11}$

Against this line of thought it could be argued that even were the residents of A and B's world no more depraved than us the obviousness of God's existence and nature would not entirely eliminate or even reduce in A and B's world freedom of the sort the free-will defence posits. If we are libertarians (as proponents of the free-will defence characteristically are), then we believe that people's choices are never entirely necessitated by anything other than the agents themselves - thus they could not be necessitated by the beliefs, knowledge, or level of depravity that an agent had acquired. So, there will be some possible world in which an agent with any level of depravity we care to specify knows of God's existence and yet still chooses to run a red light.

The residents of A and B's world as we are imagining it would have the existence of God apparent to them, but they would still be as free to be immoral as we are whilst not needing to be any more depraved. But is this really so? Given the view that it is explicability by reference to reasons that distinguishes the movements of one's body that are actions one performs from those that are merely events that one undergoes, it could be argued that it was not. On such a 
view, someone who said, 'Yes, I know with absolute certainty that there is an omnipotent, omniscient and perfectly just God; I spend my Sunday mornings running red lights rather than attending any form of religious service' would have to be interpreted as insincere; not fully understanding what they were committing themselves to with their claim that there was a God of this sort; not fully understanding the evil nature of running red lights; or suffering from some combination of these defects as it is not logically possible that anyone knows with absolute certainty that there is an omnipotent, omniscient, and perfectly just God and yet freely chooses to do evil. Knowingly doing evil is criterial, not merely evidential, of not knowing that there is a God because rationality is criterial of action. This line of argument is not open to libertarians, however. For them it is being the result of a causal chain that is initiated by an agent that distinguishes the movements of one's body that are actions one performs from those that are merely events that one undergoes, and thus irrationality can only ever be evidential - not criterial - of a particular movement's not being an action. A libertarian is committed to thinking that in some possible world an agent who has any level of depravity we care to specify, and who is absolutely certain that there is an omnipotent, omniscient, and perfectly just God, nevertheless freely chooses to do evil. However, a libertarian theist who is prepared to put God inside time has no need for this line of argument anyway, as he or she can avoid the difficulty that it is employed to deal with simply by suggesting that even God could not have chosen to create one of these worlds rather than another. God cannot infallibly predict the future free actions of creatures and a world in which agents of high levels of depravity all, nevertheless, actually never chose to do anything less than perfectly praiseworthy is immensely (physically) improbable.

It may appear that we can sidestep this whole issue. Surely God could hide Himself as effectively from the residents of A and B's world as He does from us (thus preserving in A and B's world any freedom that we have which is dependent upon His relative hiddenness from us) simply by creating them so that they lack the ability to draw the conclusion that He must exist from the evidence provided by the naturalistically inexplicable serendipity of their universe. In other words, we may posit that the residents of A and B's world just do not find it as obvious that God exists as the evidence would justify them in thinking. Perhaps they are born with a natural proclivity to gerrymandered concepts, in the sense that they take explanations in terms of them to be simple and satisfactory. Although initially attractive, in order to avoid the counter-argument that this sort of inescapable ignorance of a meta-ethically significant truth (whether or not it be based on false beliefs about the non-gerrymandered nature of their concepts) would be in itself a natural evil, one would need to suggest that it was not caused directly by God, but rather was solely the result of blameworthy failure on the part of the residents of the world, they wilfully 'hardening their hearts' (perhaps via deliberately fooling themselves into accepting as simple concepts which were in 
actuality gerrymandered) to the fact of God's existence. In other words, one would have to suggest that in A and B's universe although God does not Himself place any noetic barriers between non-divine agents and Him - it would be obvious to each resident who reflected in an unbiased way on the evidence presented to them that He existed - in fact many more residents of this world choose not to reflect in an unbiased way than do in our universe; thus, the distribution of theists and the strength of faith of these theists is similar in A and B's universe to that in ours. However, again such a manoeuvre would depend on its making sense to think of God as being able to chose to actualize one of the worlds in which the residents (or a sufficient number of them) freely chose to harden their hearts rather than one of those where they did not (and thus had His hiddenness removed to an extent that dangerously undermined their freedom). On a libertarianism that puts God inside time, whilst He could have created a world such as this, His doing so could only have been a matter of chance - even God cannot unerringly predict the future free choices of created agents.

These arguments, taken together, seem then to constitute some sort of success: they establish that there is no possible world with creatures enjoying free will of the sort the free-will defence suggests we enjoy yet suffering no natural evil; of course they only establish this for people who accept various things: for example, that God is inside time and that knowing that there is a God reduces one's freedom (unless one's depravity is increased to compensate). Despite this apparent - if somewhat qualified - success, I think that there is a fundamental flaw in the foundations on which this complex of arguments is built.

It will be remembered that early on we accepted an argument to the effect that A and B would need to be living in a partially magical world, a fully magical world - one where any object could take on any property one wanted - being one where the distinction between wishing that something happen and acting on that wish would break down, and with it the possibility of blameworthy agency (and thus moral evil, and thus free will of the sort the free-will defence suggests we enjoy). Only because we assumed that A and B could not be living in a completely magical world did arguments about how A gained knowledge of (or at least some true beliefs about) the quasi-laws operating in his world become pertinent. In a world that is only partially magical, A needs this knowledge (or at least some true beliefs) in order to be able to implement his evil intentions. Only thus did a Swinburne-style complex of arguments gain purchase. But, as I am about to show, we should not have accepted that in a completely magical world the distinction between wishing that something happen and acting on that wish would break down; arguments to the effect that in a completely magical world one could not gain knowledge of natural processes become irrelevant. To show this and yet how the conclusion that there is no possible world where creatures enjoying the sort of freedom the free-will defence suggests we enjoy yet suffering no natural evil is nevertheless true then, I want to close by drawing back and having another 
run at the task of conceiving such a world, reconsidering just how like our world a world with no natural evil would be.

\section{A perfect world?}

The other evening was bitterly cold and, in walking from my house to the postbox to post a letter, I slipped on some ice and fell. This caused a momentary sharp pain and a rather longer-lasting mildly painful bruise. In a world with no natural evil, obviously I would not have fallen. What is less obvious is precisely why. Initially, we might think that a world without natural evil would differ from ours simply in that as my feet slipped on the ice they would have righted themselves - as occasionally they do in the actual world when I nearly fall over. Such a world would not be very different from ours. It would be rather like A and B's world as we have previously described it. Further thought, however, reveals that in a world truly without natural evil, it could not be true that I would not have fallen because my feet would have righted themselves; I would not have fallen because I would not have slipped; and I would not have slipped because I would never have left the house. Why? Because having to walk - in my case only 100 yards - to the postbox in order to post a letter was, to a limited extent, in itself a natural evil even prior to my accident, given that I did not enjoy the walk. Given this, one might think that in a world truly without natural evil I would have been saved the pain and the bruise, as in such a world all one would have to do in order to post a letter would be to throw it towards a postbox; such letters would always be caught by fortuitous gusts of wind that blew them down the street and into the box. Yet further thought reveals that in a world without natural evil one would not even have to do that, have to experience the natural evil of the exertion of throwing a letter. Nor indeed would one have to experience the exertion of writing a letter. In such a world, the mere intention that a message be conveyed to another would be sufficient to make that other aware of that message.

From the fact that my having a particular body distinct from others is my being unable to influence all sections of the universe by direct acts of my will, we can conclude that particular embodiment within a universe necessitates limitations that are potentially natural evils. They are only potentially natural evils, I suggest, for so long as one is enjoying one's embodiment in one section of the universe rather than another, this embodiment need not be a harm. There is nothing intrinsically bad in writing letters, walking to postboxes, and so on. Therefore, it is only a natural evil to have to write a letter, walk to a postbox, and so on if one does not enjoy these activities as ends in themselves, regardless of their also being means to an end that one wishes to achieve. A world without natural evil would thus have to be one where the residents did not have to write letters to one another, walk to postboxes, and so on, when doing so hampered them in achieving their ends. It might be one where they might choose to do so anyway when it 
did not. It is important to note that at least some of the potential natural evils imposed by a particular embodiment are not potential natural evils imposed by contingent truths about the particular sections of the universe residents might happen to have as their bodies. They are potential natural evils logically necessitated by what it is to have a body distinct from others in a universe, namely that it is to be unable to control everything in the universe by a direct act of the will. Thus, we may conclude that unless localizing themselves in some particular place was more or less directly one of their purposes (or at least was not contrary to one of their purposes), the residents of a world without natural evil would be 'disembodied and able to influence any part of the universe by a direct act of the will' or, what is equivalent, have the whole of the universe as their body.

There would seem to be a problem for the relatively irenic picture we have painted thus far generated by the presence of more than one agent in this world. Other people can, through no fault of their own, be inconvenient by forming desires equally reasonable but incompatible with one's own. What if one resident of the world without natural evil that we are trying to imagine innocently wanted a particular section of the universe to behave in one way to give him/her the pleasures of embodiment there on a sunny day and another innocently wanted it to behave in another way to give him/her the pleasures of embodiment there on a rainy day? At least one would have to have their desire frustrated, something which would then be a natural evil for them. To keep our thought-experiment going, we thus have to posit Humean-miraculous intervention or equivalent natural necessities preventing conflicting and blameless desires arising. In a world without natural evil, it would have to be the case that one resident's innocently willing $x$ prevented any other resident's innocently willing anything incompatible with $x$.

Here, an argument we have previously considered becomes relevant once more. Such Humean-miraculous intervention or something effectively equivalent would generate fantastically gerrymandered quasi-laws, something which we have seen could be argued to threaten free will, as the residents could never understand or build a folk science upon them. It might, prima facie, seem that they could understand them - sometimes they would find themselves able to have certain sorts of desires, e.g. to become embodied in a particular part of the universe and find when they get there that it was sunny (if no-one had got there first with a contrary desire), and sometimes they would find themselves unable to have those desires (if someone had). But they could only gather this sort of experience and through it learn of this sort of quasi-law if they sometimes tried and failed to form a particular desire. Then their failing to form that desire would be the frustration of another higher-order desire (to form the desire) and this would be in itself a natural evil for them. Thus, in a world with no natural evil the residents would never know any quasi-laws or thus be able to form a folk science. 
Previously we accepted an argument to the effect that such an inability would be inimical to the possibility of their performing actions. However, we can now see that it need not matter. In a world where every agent gets whatever it is that she wants directly, not needing to do anything in order to get it, no agent needs knowledge of quasi-laws to get what he wants. So our previous argument to the effect that freedom requires knowledge of natural quasi-laws and processes (on which any endorsement of a Swinburne-style argument for our conclusion depends) simply does not apply to a world truly without natural evil, such as we are trying to imagine - a purely magical world where each resident gets what she wants directly.

What of the argument that we previously accepted as sound, to the effect that for the real possibility of blameworthy agency (without which there could not be moral evils and hence - ex hypothesi - there would not be freedom of the sort the free-will defence suggests we enjoy), we have to preserve the distinction between wishing that harm would befall someone, deciding to act on that wish, and doing so, and that in a completely magical world these distinctions would break down? Closer inspection reveals that we should not have accepted it as sound. The second half is not secure. My train of thought is sometimes under the direct control of my will. Someone can annoy me, giving me the desire to dwell on an evil fantasy involving their suffering some unpleasant fate; I can decide to give in to that desire rather than do what I think I ought, push such thoughts from my mind and get on with something else; thus I can act on it, fantasizing about their suffering some unpleasantness. I use nothing - or at least nothing I am aware of - as a means to my end. Yet surely I can be blameworthy for letting my imagination dwell on their suffering some unpleasantness. I can achieve my end of fantasizing about someone else suffering by a direct act of the will, yet I can separate the process of coming up with an initial desire for that end from the process of deciding to bring it about by willing that it come about, for sometimes I give in to such desires and sometimes I do not. Thus, even were one to be able to get anything one was capable of wanting by a direct act of the will, it would not follow that one could not separate the process of coming up with an initial desire for some end from deciding to bring that end about by willing it.

So far, it seems then that even though the residents of a world without natural evil would be under the control of natural laws, they need not suffer in any way as a result of them. For it seems that we may posit that Humean-miraculous intervention or natural necessities (of which they are indeed ignorant) prevent their desires ever being directed towards things that would be denied them by randomness, the operation of natural laws on the initial or boundary conditions of the universe, or the satisfaction of other agents' blameless desires. This is just as well for the project of coherently describing a world with created free agents yet no natural evil, for being under the control of natural laws the operations of which 
one cannot actually alter by direct acts of the will is a function of being less than omnipotent, i.e. of being someone other than God. We have shown that such finitude need not lead to desires being frustrated, for the residents may-like McEar (a man who is only able to scratch his ear yet can do anything he wants given that his only want is to scratch his ear) - have limited desires. Unlike McEar - who seems rather obviously to suffer from natural evils even though he can get anything he wants - the residents of the world we are imagining might, it seems, have a rich and varied range of desires, all of which would of course be satisfied (unless some blameworthy agency intervened) as a result of these Humean-miraculous or equivalent acts of God. It seems that in this world each resident would find herself in the happy position of - in the absence of blameworthy counter-agency - apparently being able to control all aspects of her environment by direct acts of the will, i.e. extend, shrink, and control the properties of her body at will. Residents would never 'tread on one another's toes' (unless they intended to) as natural necessities of which they were blissfully ignorant would prevent their ever having incompatible but equally blameless desires. So far then, so good. Our conceptualization of a world with free creatures yet without natural evil has avoided Swinburne's counter-arguments. Would creatures in such a world enjoy any reduction relative to us in the amount of freedom of the sort that the free-will defence suggests we enjoy? They would, a very great one.

The argument in essence is this. For an agent to suffer from a natural evil is for him or her to have his or her interests less than perfectly served by natural facts, i.e. randomness or natural laws operating on the initial or boundary conditions of the universe. Were a certain agent to desire something that would be against the interests of another agent, then one of these agents would have - of logical necessity - to have their interests less than perfectly served by natural facts on the assumption (central to the free-will defence, which we are accepting as valid) that it is in one's interests to have effective freedom even when one uses it for evil. One agent would have to suffer a natural evil. To avoid this evil, the residents of the world we are trying to imagine would have to have the freedom to choose to harm one another eliminated by Humean-miraculous intervention of something effectively equivalent, and this elimination would itself be a great natural evil if the free-will defence for the problem of moral evil is valid. Let us look at this argument in more detail.

To have effective freedom to harm another requires one to have more power than the other, and one person's having more power than another must be a consequence of natural facts, i.e. facts which are solely the result of randomness or the operation of natural laws on the initial or boundary conditions of the universe. Let us take an example. Suppose that, rather than wishing to kill her, A wished B merely to suffer from ten minutes of excruciating agony. Either A would get his wish (in which case B would find that natural facts less than perfectly 
served her interests) or B would be able to block A's malevolent intention (in which case A would have his interests less than perfectly served by natural facts). Now, it might seem that one could avoid this conclusion by suggesting that in this world one person's having more power than another was itself always the result of blameworthy non-divine action, never the result of natural facts. We might posit that A, wishing B to suffer from ten minutes of excruciating agony, first blameworthily removed by a direct act of his will B's 'blocking' power and then, by a direct act of his will, initiated B's pain. Here then, one might think, it would not be randomness or the operation of natural laws on the initial or boundary conditions of the universe that had less than perfectly served her interests; it would be A. But such a manoeuvre would simply push the problem one step back. Why cannot B block A's attempt to remove her blocking power? This could only be because she started from a position of having less power than A, a fact which A had not created by a blameworthy action but rather one which must be true if he is ever to action a blameworthy intention towards her. This disparity in their power must therefore be, at some level, a natural fact. This natural fact is something which fails to serve B's interests as well as it might, i.e. it is a natural evil for her. (Of course, if the natural fact were to be that $B$ had more power than $\mathrm{A}$, then in effectively blocking his malevolent intentions towards her, she would - blamelessly - allow A to suffer from a natural evil: a natural fact would fail to perfectly serve his interests, the effective operation of his freedom.)

The general point is that when someone wishes to harm another that person wishes to do something which is against the other's interests. On the assumption that it is in one's interests to have effective free will even when one uses it for evil (which is an assumption essential to the free-will defence), whichever way reality goes, at least one person will have their interests less than perfectly served by what must be at some level a natural fact; they will experience a natural evil. A and B cannot be equally powerful if either is to have their interests perfectly served when they conflict - of logical necessity reality cannot 'go both ways' and the fact that one is less powerful than the other must ultimately - if it is not due to a Humean-miraculous intervention - be the result of randomness or the operation of natural laws on the initial or boundary conditions of the universe. No non-divine agent in any way affected randomness; the laws of nature; or the initial or boundary conditions of the universe; ipso facto they did not affect them in any blameworthy way. A disparity in power when one's interests conflict with those of another must therefore be a natural evil for someone. So, to preserve our claim that this is a world without natural evil a moment longer, we would need to posit that Humean-miraculous intervention or equivalent natural necessities prevented any agent desiring anything that was against the interests of another. Thus, could we say that no resident need suffer this natural evil. Of course we would then need to admit that the only moral evils that were possible in this 
world were those of self-harm. Such a manoeuvre would generate a drastic reduction (relative to our world) in the choices open to the residents of a world without other natural evils; I say 'other' because a naturally imposed inability to be able to choose to affect others for good or ill would obviously be a very severe naturally imposed diminution in creatures' freedom as it is understood by the free-will defence, something which the free-will defence suggests would be in itself a natural evil for these creatures.

In order to drive home quite how badly off the people in such a world would be, let us consider by way of example the great good that we enjoy of largely 'uncensored' communication, that is to say communication that reaches us from 'senders' unfiltered by what it is that someone other than the senders intends us to perceive. Communication of this sort requires one to receive ideas, some of which at least would occur even were one to desire them not to (otherwise one would oneself be a 'censor'), so that ideas arising as a result of communication with another can be epistemically separated from naturally occurring whimsies or the manifestations of non-mind-directed processes. In a world without other natural evils then, there could not be uncensored communication and - without it - the residents could never know whether or not there was any communication at all; they could never enter into any sort of relationship with one another. Some relatively structured thoughts might pop into their minds unbidden, but as the occurrence of none of these would be contrary to their desires (for otherwise they would be at some level natural evils for them) and as all of these thoughts would appear immediately susceptible to modification by their wills (for otherwise, again, they would be at some level natural evils for them), they could never be recognized as the manifestations of another's mind.

Of course, preserving the (by now pretty obviously false) picture of this as being a world without natural evil for a moment longer would then require us to posit Humean-miraculous intervention or equivalent natural necessities preventing any resident of this world ever desiring communication with anyone else. Thus, their desires need not be frustrated. The residents would need to be contented solipsists: not only could they not influence anybody else, they could not want to influence anybody else. However, to be denied by Humean-miraculous intervention or equivalent natural necessities the good of relationship with others would be to suffer a great evil regardless of whether or not one realized it; and to be denied the possibility of desiring relationship with others would actually - I suggest - make one's condition even worse. Contented solipsists suffer great evil even though they do not realize it; and indeed the evil they suffer is greater for being one they do not realize they suffer. Whatever one makes of this last point, the hypothesis that there might be a world where creatures enjoyed the sort of freedom that the free-will defence suggests we enjoy yet suffered no natural evil has manifestly shaken itself apart. 


\section{Conclusion}

According to the free-will defence for the problem of moral evil, moral evils are the result of the free actions of agents other than God, God Himself merely providing the opportunity for such free actions, an opportunity which is in itself a good, and a good that is good enough to make the evils that it occasions worthwhile, or at least good enough to make God morally justifiable in risking creating such a world. I hope to have shown that natural evils are a logically necessary result of God's having created a universe where creatures enjoy freedom of the sort the free-will defence suggests we enjoy, and in doing so opened the possibility of extending the free-will defence to the problem of natural evil.

Of course, an argument showing that creatures enjoying the sort of freedom that the free-will defence posits we enjoy must suffer some natural evil does not show that the free-will defence is valid as such. It does not show that - supposing that it is, and further that the amount of moral evil in the world is indeed compensated for by the amount of the good of free will, or at least that it would have been reasonable for God to think that it would have been prior to Creation - the actual natural evils in the world do not 'tip the balance' against theism. And it does not show that God would have been morally justified in creating this world even were it to be shown to be one where the good outweighed the evil, or one which He could reasonably have anticipated would have had this feature, for it does not show that God was not under an obligation not merely to create a world that was or that He could reasonably have anticipated would have been 'good enough', but to do better than that - to create 'the best of all possible worlds'. There are then many aspects of the problem of evil that we have not addressed. All our argument has shown is that it may be possible for those who accept that the free-will defence is valid and that God need not create the best of all possible worlds to treat the problem of as fundamentally one problem. ${ }^{12}$

\section{Notes}

1. Richard Swinburne has done so in a number of places: The Existence of God (Oxford: Clarendon Press, 1979), esp. ch. 11; 'Knowledge from experience, and the problem of evil', in W. Abraham and S. Holtzer (eds) The Rationality of Religious Belief (Oxford: Clarendon Press, 1987); and in Providence and the Problem of Evil (Oxford: Clarendon Press, 1998).

2. Swinburne The Existence of God, 207.

3. The same point may be made against Moser's version of the argument as expounded in his 'Natural evil and the free will defense', International Journal for Philosophy of Religion, 15 (1984), where his premise 8 (54) states that 'some morally responsible human agents must acquire a concept of evil through experience of natural evil'.

4. Swinburne himself says in a later discussion of his argument that 'God could ensure that men were given moral concepts ... without their having any experience of harsh moral realities'; Swinburne 'Knowledge from experience, and the problem of evil', 155-156. He thus augments the argument of the passage quoted above with another to which we shall come in due course.

5. This is contrary to the suggestion of O'Connor who states that 'while it may indeed be highly improbable, it is not logically impossible that human beings should become equipped with a knowledge 
of good and evil another way, say, innately'; D. O'Connor 'Swinburne on natural evil', Religious Studies, 19 (1983), 66.

6. For example, Swinburne Providence and the Problem of Evil, 177.

7. Swinburne 'Knowledge from experience, and the problem of evil', 157.

8. My discussion assumes that running a red light is an evil regardless of the consequences. If this is doubted, a simple change of example would be required to make my point.

9. Swinburne Providence and the Problem of Evil, 206.

10. Ibid., 207.

11. Ibid., 167.

12. I am grateful for having discussed these issues with Peter Byrne, Douglas Hedley, Dave Leal, Richard Swinburne, and Mark Wynn; and for the comments of two anonymous referees for Religious Studies on an earlier draft of this paper. 